Human Ethology Bulletin 33 (2018)4: 1-2

Letter from the Editorial Board

\title{
EDITORIAL FOR SPECIAL ISSUE HighLIGHTING STUDENT RESEARCH IN HUMAN ETHOLOGY
}

\author{
Maryanne L. Fisher1,2 \& Ian D. Stephen ${ }^{3}$ \\ 1Department of Psychology, Saint Mary's University, Halifax, NS, B3H 3C3 \\ ${ }^{2}$ Affiliate Faculty, Kinsey Institute, Bloomington, Indiana, USA. \\ 3Department of Psychology and Perception in Action Research Centre, Macquarie University, North \\ Ryde, 2109 NSW, Australia
}

"Truth in science can be defined as the working hypothesis best suited to open the way to the next better one"

Konrad Lorenz

"It is the supreme art of the teacher to awaken joy in creative expression and knowledge"

Albert Einstein

Human ethology is an area of unarguable importance within studies of evolutionary perspectives of human behaviour, cognition, emotion, and motivation. Unlike other, similar fields, placing a 'Tinbergian' perspective at the centre of our discipline ensures that we pursue a deep (i.e., multi-layered) understanding of human behaviour, and the influence of Lorenz ensures that we go to great lengths to watch behaviour occur in its natural environment. Taking into account both proximal and ultimate causes, human ethology is a science, relying on the methods of induction and observation (Tinbergen, 1963). The heart of a human ethologist is truly that of a curious naturalist. 
Whilst our near neighbours, human behavioural ecology and evolutionary psychology, continue to grow (Brinkman, 2011; Webster, 2007), driven by the availability of textbooks, public familiarity with the name 'evolutionary psychology', easier and more convenient methodologies such as surveys, and a glut of available supervisors, they tend to focus on a relatively small group of topics such as life history trade-offs, mate choice, and parasite resistance (see Table 1, Owens, 2006). In contrast, the remit of human ethology remains all of the human mind and behaviour.

The quotation attributed to Lorenz at the start of this Editorial brings to mind the dynamic nature of science. In our search for knowledge and understanding we must be open to alternative approaches, but at the same time, rely on sound methodology such as that used in classical ethology. The second quotation highlights the need to inspire future scholars to see the way that our discipline can contribute to the quest for scientific knowledge. We must continue to promote the principles of our field with our students and colleagues.

Our goal with this special issue was to showcase the work of students in human ethology. This special issue highlights cutting-edge research by the next generation of human ethologists. Some of the papers have been written by undergraduate students, and others by teams of graduate students. This range in educational attainment shows that individuals, once trained in basic ethology, can become human ethologists producing important and novel insights into the human mind and behaviour.

We would like to thank the International Society for Human Ethology for their support, as well as the students who worked with us to create this special issue. We also thank the Editor in Chief, Colin Hendrie, for all of his assistance, Assistant Editor for this special issue, Geneva Reid, for her help, as well as the production staff Susanne Schmehl and Kathrin Masuch, the reviewers for the article, and the authors themselves.

\section{REFERENCES}

Brinkmann, S. (2011). Can we save Darwin from evolutionary psychology? Nordic Psychology, 63(3), 50-67. DOI

Owens, I. P. F. (2006). Where is behavioural ecology going? Trends in Ecology and Evolution, 21(7), 356-361. DOI

Tinbergen, N. (1963). “On aims and methods of ethology." Zeitschrift für Tierpsychologie, 20, 410-433. DOI

Webster, G. D. (2007). Evolutionary theory's increasing role in personality and social psychology. Evolutionary Psychology, 5(1). DOI 